\title{
Experimental evidence of reduced diversity of seedlings due to climate modification in a Mediterranean-type community
}

\author{
FRANCISCO LLORET* JOSEP PENUELAS † and MARC ESTIARTE† \\ ${ }^{*}$ CREAF (Center for Ecological Research and Forestry Applications)-Unitat d'Ecologia, Departament Biologia Animal, Biologia \\ Vegetal i Ecologia, Edifici C, Universitat Autònoma de Barcelona, 08193 Bellaterra, Barcelona, Spain, †Unitat Ecofisiologia CSIC- \\ CEAB-CREAF, CREAF (Center for Ecological Research and Forestry Applications), Edifici C, Universitat Autònoma de Barcelona, \\ 08193 Bellaterra, Barcelona, Spain
}

\begin{abstract}
We are still lacking in experimental evidence of the effects of climate change on the richness of plant species under field conditions. We report a decrease in the species richness of recruited seedlings in a Mediterranean shrubland in experimentally induced drought and warming over 4 consecutive years. Drought decreased the number of emerging seedlings and their respective species richness. Warming also decreased seedling species richness, but it did not affect the number of emerging seedlings. Species that produce fewer recruits are more likely to disappear in drier or warmer scenarios. However, when the effect of induced climate treatment was greatest, the more abundant species in control stands were not necessarily the ones least affected by treatment; in other words, species-idiosyncratic responses may occur. These results show that demographic processes are sensitive to minor climate changes, with probable consequences on the diversity and structure of the future plant communities.
\end{abstract}

Keywords: climate warming, drought, global change, mediterranean ecosystems, seedling dynamics, species diversity, species recruitment.

Received 26 June 2003; revised version received 8 October 2003 and accepted 13 October 2003

\section{Introduction}

The understanding of the effects of climate change, increasing atmospheric $\mathrm{CO}_{2}$ concentrations and transformations in the use of land on the composition of ecosystem species has become one of the most important challenges facing ecologists, because of their consequences on long-term ecosystem functioning (Körner, 2000; Chapin et al., 2001; IPCC, 2001). Habitat loss and fragmentation are now recognized as major causes of biodiversity loss. Climate-induced changes in species distribution and abundance may also alter complex networks of species interactions and cause significant shifts in diversity patterns within communities (Tilman, 1998; Chapin et al., 2001). Predictions of the effects of climatic change on biodiversity have been often based on the analysis of species assemblies in correlation with expected new climate scenarios (Sykes

Correspondence: Francisco Lloret, fax 3493 5811312, e-mail: Franciso.Lloret@uab.es et al., 1996; Iverson \& Prasad, 1998), or on monitoring changes in the local abundance of species (Lewis-Smith, 1994; Alward et al., 1999) or on the distribution range of particular taxa (Parmesan et al., 1999; Warren et al., 2001; Walther et al., 2001; Peñuelas \& Boada, 2003). More experimental back-up is, therefore, needed to assess the effects of climate change on the species composition of communities, and particularly on species diversity patterns. Climate manipulation should be applied to the whole set of species coexisting in the field, where demographical and ecophysiological processes are often operating at stand levels. This experimental approach can be addressed by temperature or rainfall manipulations that have established the links between climate changes and biological processes in ecosystems (Chapin et al., 1995; Harte \& Shaw, 1995; Luekewille \& Wright, 1997; Wright, 1998; Fay et al., 2000; Shaver et al., 2000; Valpine \& Harte, 2001; Rasmussen et al., 2002). Although this approach has been used to estimate changes in abundance or recruitment patterns of dominant species in a community 
(Parsons et al., 1995; Henry \& Molau, 1997; Robinson et al., 1998; Weltzin \& McPherson, 2000; Weltzin et al., 2000; Buckland et al., 2001), we need more accurate information on the effects of climate manipulation on parameters describing the whole community, such as species diversity or species relative abundance (Sternberg et al., 1999).

Early development stages of plants are expected to be more sensitive to environmental constraints than adult stages, as supported by the typical pattern of decreasing risk of death from birth in plant populations (Watkinson, 1997). Weltzin \& McPherson (2000) showed that seedling emergence and the recruitment of Quercus seedlings in North America savannah ecotones were more sensitive to climate manipulation than seedling survival and growth. Seedling establishment has been often used to monitor the effects of climate change on plant communities (Lewis-Smith, 1994; Taylor, 1995; Wookey et al., 1995; Sternberg et al., 1999; Kullman, 2002). Seedling dynamics is also relevant in determining future species composition and vegetation type, as well as in creating indirect effects on the ecosystem functioning (Schulze et al., 1996). Seedlings are, therefore, particularly suitable for detecting future alterations in community composition as a consequence of climate change.

Changes in the species composition of the community can be analysed by comparing patterns of species abundance under different climate regimes. The analysis of effects of climate treatments on the relative abundance of seedlings gives rise to four possible hypotheses, all open to testing, about the relationship between species abundance and the likelihood of disappearance under new climatic conditions (Fig. 1):

(i) The less abundant species are more likely to disappear (selection hypothesis). Less abundant species could be growing at the extremes of their appropriate environmental conditions and their abundance is therefore more likely to decrease with increasingly unsuitable conditions, until the species is eventual lost. This hypothesis, which amounts to a negative selection of these rare species due to climate change, is supported by a correlation between the likelihood of decline and the respective speciesrank abundance, i.e., by a nonlinear relationship between the relative abundance of species in treatment and in control stands, with zero values in climate change (treatment) stands for those species which are rare in control stands. It is also expected that a disproportionate loss of the less abundant species would result in a decrease in the evenness of the species abundance distribution.

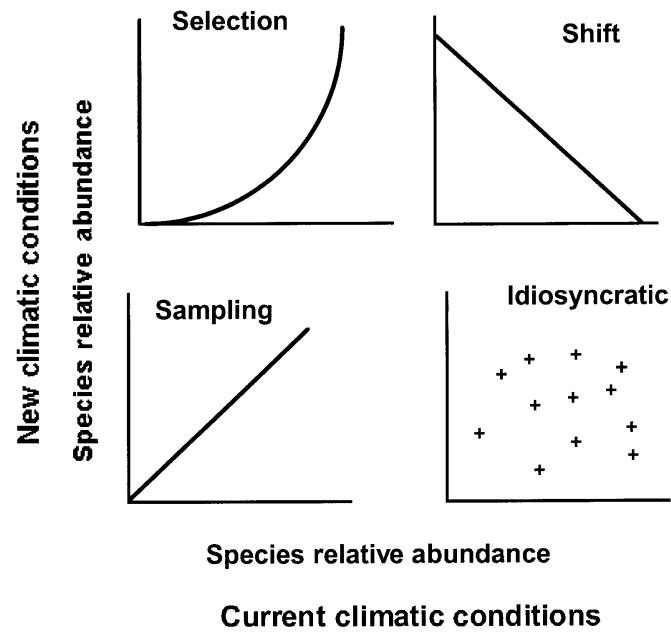

Fig. 1 Hypotheses with respect to species abundance under new climatic conditions and current climatic conditions. The selection hypothesis proposes that less abundant species are more prone to decrease and eventual disappearance under new conditions. The shift hypothesis proposes a change in species composition due to the decline of currently abundant species. The sampling hypothesis proposes that species decrease in proportion to their current abundance. The idiosyncratic hypothesis proposes no relationship between current and future abundances.

(ii) The most abundant species are more likely to disappear (shift hypothesis). Under new conditions, some previously rare species could attain dominance, while former dominant species are diminished. This hypothesis assumes an abrupt shift, which would need an extreme event. In the most extreme case, a negative relationship between the relative abundance of species in treatment and in control stands may be found.

(iii) Species losses are proportionally related to species abundance (sampling hypothesis). This hypothesis establishes that if we reduce the number of seedlings from each species at a rate proportional to its abundance, the least abundant species in terms of control stands will also be the least abundant with respect to treatments. They are therefore stochastically more likely to disappear. In this case, a linear, positive relationship between treatment and control stands is expected.

(iv) The loss of species is unrelated to its respective abundance (idiosyncratic hypothesis). This hypothesis would result in a nonsignificant relationship between the relative abundance of species in treatment and in control stands.

We report the results from an in situ climate manipulation experiment, using a nonintrusive procedure in which precipitation and temperature were manipulated 
for 4 consecutive years. We studied the response of Mediterranean shrub vegetation to increasing drought and climate warming. Several studies manipulating climate have been performed in cold and moist temperate and Arctic ecosystems (Chapin et al., 1995; Harte \& Shaw, 1995; Parsons et al., 1995; Henry \& Molau, 1997; Luekewille \& Wright, 1997; Wright, 1998; Buckland et al., 2001; Valpine \& Harte, 2001; Rasmussen et al., 2002), but more information is needed for arid and semi-arid environments (but see Weltzin \& McPherson, 2000; Shaw \& Harte, 2001). More specifically, we addressed the effects of induced climate change on the number and relative abundance of plant species recruiting in a natural community. We expected water availability to be the most important factor in this Mediterranean-type ecosystem, due to the combination of high summer temperatures and low rainfall (Specht et al., 1983; Larcher, 2000). These effects would particularly influence seedling recruitment (Borchert et al., 1989; Lloret, 1998).

\section{Material and methods}

\section{Study site}

The experiment was performed in Garraf Natural Park (Barcelona, Spain) $\left(41^{\circ} 18^{\prime} \mathrm{N}, 1^{\circ} 54^{\prime} \mathrm{E}\right)$ at $300 \mathrm{~m}$ asl. The climate is Mediterranean with cool, moderately wet winters and hot, dry summers. Stony and basic soils have developed over Cretaceous limestone. The vegetation is a short shrubland (less than $1 \mathrm{~m}$ high) growing on old agricultural terraces (vineyards), which were abandoned about 100 years ago and have been burnt several times since then. The last fire occurred in 1994, so it is an early successional community dominated by woody species such as the nanophanerophytes Erica multiflora L., Globularia alypum L, and Dorycnium pentaphyllum Scop., Helianthemum syriacum (Jacq.) Dum.-Cours. and the chamaephytes Fumana ericoides (Cav.) Gandg., Fumana thymifolia (L.) Spach ex Webb, Coris monspeliensis L. and Polygala rupestris Pourr.

\section{Drought and warming treatments}

The experiment was conducted on nine $20 \mathrm{~m}^{2}$ $\left(5 \times 4 \mathrm{~m}^{2}\right)$ stands, where warming treatment (from night reradiation to atmosphere exclusion by reflective covers), drought treatment (automatic, seasonal exclusion of rainfall by nonreflective, water proof transparent plastic covers) and control were applied (three stand replicates per treatment). Since the number of replicates was low, we ensured the homogeneity of the stands before the start of the experiment. Estimates of seedling emergence in the season prior to the experi- ment were not available, but there were no significant differences between the stands for the different treatments as regards either the total plant cover (one-factor ANOVA, $F_{2,6}=0.26, P=0.610$ ) or the cover of the dominant species producing seedlings (E. multiflora, G. alypum, D. pentaphyllum, Fumana sp pl, H. syriacum) (one-factor ANOVA; $F_{2,6}=0.48, P=0.641 ; \quad F_{2,6}=0.54$, $P=0.609 ; \quad F_{2,6}=0.61, P=0.572 ; \quad F_{2,6}=1.49, P=0.207 ;$ $\left.F_{2,6}=1.18, P=0.371\right)$. The warming treatment was first applied in April 1999, and it has remained active to this day. The drought treatment has been in operation for the same period. Drought treatment prevented water entering the system during plant growth seasons: in spring-summer and in autumn (Beier et al., 2004; Peñuelas et al., 2004). Three untreated control stands, with a light scaffolding similar to those used for the warming and drought treatments but without any cover, were installed for comparison.

Warming treatment consists of a coverage that is automatically activated according to preset light $(<2001 x)$ conditions. Solar energy is accumulated in the ecosystem during the day and a fraction of the energy is reradiated back to the atmosphere at night as long-wave IR radiation. The night-time covering of the ecosystem with the reflective curtains (ILS ALU, AB Ludvig Svenson consisting of $5 \mathrm{~mm}$ wide aluminium strips knitted into a high-density polyethylene mesh) reduces the loss of IR radiation. Since global warming is principally caused by a reduced loss of long-wave IR radiation from the Earth back into the atmosphere due to the greenhouse gas accumulation in the atmosphere, warming is expected to occur mainly at night (Karl et al., 1993; IPCC, 2001). This expectation is supported by the analysis of global temperature records showing that the observed global temperature increase of $0.6^{\circ} \mathrm{C}$ has been due to larger increases during the night compared to increases during the day (Easterling et al., 1997). The warming covers were automatically removed during rain events as a result of triggering from rain sensors. We monitored air temperature at $20 \mathrm{~cm}$ above the soil surface and soil temperature at depths of 0,2 and $10 \mathrm{~cm}$ using thermistors (Pt100 1/3DIN, Desin Instruments, Barcelona, Spain) wired to data loggers.

The drought stands were constructed in a manner similar to the warming stands except that the cover material was a transparent plastic and the movements of the covers was only governed by the rain and the wind. During the period in which the drought treatment was applied, the rain sensors activated the roof to cover the stands whenever it rained, and they removed the covers when the rain stopped. The roof movement related to precipitation was regulated by a tipping bucket rain gauge with a sensitivity of $0.5 \mathrm{~mm}$ rain, assuring a fast response of the roofs to precipitation 
events. The drought stands were run parallel to the control stands for the part of the year without drought treatment. The curtains were removed automatically if the wind speed exceeded $10 \mathrm{~m} \mathrm{~s}^{-1}$ to avoid damage to the equipment. No side enclosures were put up for either of the treatments. The water content in the first $15 \mathrm{~cm}$ of soil was monitored by time domain reflectometry (TDR) measurements. The precipitation on the site was also monitored by a standard rain gauge.

\section{Seedling recruitment records}

We recorded, from emergence to death, all emerging seedlings belonging to woody, perennial species in eight randomly selected quadrats $\left(400 \mathrm{~cm}^{2}\right.$ : $20 \times 20 \mathrm{~cm}^{2}$ ) permanently sited in the same place in each stand. Seedlings, that is, plants germinated in the respective current growth season, were identified by the presence of cotyledons or their scars and by the absence of lignifications. The coordinates of each seedling within the quadrat were recorded, and a small coloured pin was placed close to each seedling in order to facilitate its identification during subsequent samplings. The fate of each seedling could thus be tracked throughout the entire study period. Herbaceous species were rare in this community and they were not considered in this study. Sampling dates corresponded to the start of the emerging season (fall to early winter), and to the start of the dry season (early summer), with occasional intermediate census (winter): March 1999, June 1999, October 1999, February 2000, June 2000, February 2001, June 2001, November 2001, February 2002 and June 2002. Seedlings of the following species were recorded: Argyrolobium zanonii (Turra) P.W. Ball, Bupleurum fruticescens L., Coronilla minima L., C. monspeliensis L., Dorycnium hirsutum (L.) Ser. in DC., D. pentaphyllum Scop., E. multiflora L., F. ericoides (Cav.) Gandg., F. thymifolia (L.) Spach ex Webb, G. alypum L., Helichrysum stoechas (L.) Moench, H. syriacum (Jacq.) Dum.-Cours., Ononis minutissima L., Pistacia lentiscus L., P. rupestris Pourr., Rosmarinus officinalis L., Teucrium chamaedrys L., Thymus vulgaris L. and Ulex parviflorus Pourr (Table 3).

\section{Data analysis}

Comparisons between treatment and control stands were performed by repeated measures ANOVA, with treatment as between-subject factor, cohort as withinsubject factor and the number of species and number of seedlings as the response variables. We used this model to analyse the number of seedlings, the species richness of seedlings and the Shannon $H^{\prime}$ evenness index. For the analysis of the number of seedlings we considered the average values of the eight $400 \mathrm{~cm}^{2}\left(20 \times 20 \mathrm{~cm}^{2}\right)$ quadrats in each stand. For the species richness, we pooled the seedlings emerging in the eight quadrats per stand. The Shannon $H^{\prime}$ evenness index was calculated for each stand by pooling the data of all the eight quadrats within each stand $\mathrm{H}^{\prime}=-\left(\sum_{i}^{S} p_{i} \log _{2} p_{i}\right) / \log _{2} S$, where $p_{i}$ is the relative abundance of the seedlings of each species and $S$ is the respective number of species.

We also analysed the number of surviving, established seedlings present in June 2002, which emerged during the period of the experiment from October 1999 to June 2001. This variable summarizes the emergence and survival of the year 2000 and year 2001 cohorts jointly. Comparisons between the treatment and control of these seedlings were performed by one-way ANOVA.

Comparisons of seedling survival between treatments were performed by Mantel-Cox test. We considered separately those seedlings, which were present in June 1999 and June 2000 and those that were recorded up to June 2002. For this analysis, we pooled all the seedlings emerging in the three stands with the same treatment. No transformations were needed in these analyses to attain the homoskcedastic and additive criteria.

Changes in the relative abundance of species as a consequence of treatments were analysed by linear regressions on the species relative abundance in control vs. treatment stands for each year. We also performed logistical regressions on species-rank abundance in control stands vs. likelihood of an increase or decrease in the rank abundance in treatment stands from the same year. We estimated changes in rank abundance patterns in different years by a repeated-measures ANOVA, with year as within-subject factor, and the difference in species-rank abundances between control and treatments as the response variables.

The statistical analyses were performed following the StatView 5.0.1. package procedure (Anon., 1998).

\section{Results}

Drought treatment significantly reduced soil moisture when compared to control stands (Table 1). This effect appeared several months after the start of the experiment, and it was particularly noteworthy in autumn and spring-summer, when the waterproof covers were active and the seedling establishment was greatest (Lloret, 1998). There was an important interyear variability in the effect of the drought on soil moisture, and this was particularly great in the autumns of 2000 and 2001. Soil moisture was not significantly reduced by the coverage of the warming stands (Table 1), but it was lower than in controls in several months. Although warming coverage was only active at night, the effect 
Table 1 Monthly mean soil moisture (water volume per soil volume; SD values in brackets) of the three plots pertaining to each treatment

\begin{tabular}{|c|c|c|c|c|c|c|c|c|c|c|c|c|}
\hline & January & February & March & April & May & June & July & August & September & October & November & December \\
\hline \multicolumn{13}{|l|}{1999} \\
\hline Control & & & $\begin{array}{c}0.15 \\
(0.02)\end{array}$ & $\begin{array}{c}0.17 \\
(0.02)\end{array}$ & $\begin{array}{c}0.18 \\
(0.01)\end{array}$ & $\begin{array}{c}0.13 \\
(0.02)\end{array}$ & $\begin{array}{c}0.10 \\
(0.03)\end{array}$ & $\begin{array}{c}0.11 \\
(0.02)\end{array}$ & $\begin{array}{c}0.29 a \\
(0.03)\end{array}$ & $\begin{array}{c}0.29 a \\
(0.03)\end{array}$ & $\begin{array}{c}0.33 a \\
(0.03)\end{array}$ & $\begin{array}{c}0.29 a \\
(0.03)\end{array}$ \\
\hline Drought & & & $\begin{array}{c}0.17 \\
(0.01)\end{array}$ & $\begin{array}{c}0.15 \\
(0.01)\end{array}$ & $\begin{array}{c}0.14 \\
(0.03)\end{array}$ & $\begin{array}{c}0.12 \\
(0.02)\end{array}$ & $\begin{array}{c}0.11 \\
(0.02)\end{array}$ & $\begin{array}{c}0.11 \\
(0.02)\end{array}$ & $\begin{array}{c}0.18 b \\
(0.05)\end{array}$ & $\begin{array}{c}0.16 b \\
(0.04)\end{array}$ & $\begin{array}{c}0.17 b \\
(0.02)\end{array}$ & $\begin{array}{c}0.16 b \\
(0.04)\end{array}$ \\
\hline Warming & & & $\begin{array}{c}0.14 \\
(0.03)\end{array}$ & $\begin{array}{c}0.15 \\
(0.02)\end{array}$ & $\begin{array}{c}0.16 \\
(0.03)\end{array}$ & $\begin{array}{c}0.12 \\
(0.02)\end{array}$ & $\begin{array}{c}0.10 \\
(0.02)\end{array}$ & $\begin{array}{c}0.10 \\
(0.02)\end{array}$ & $\begin{array}{c}0.26 a \\
(0.02)\end{array}$ & $\begin{array}{c}0.26 a \\
(0.03)\end{array}$ & $\begin{array}{c}0.31 \mathrm{a} \\
(0.05)\end{array}$ & $\begin{array}{r}0.26 a \\
(0.03)\end{array}$ \\
\hline \multicolumn{13}{|l|}{2000} \\
\hline Control & $\begin{array}{c}0.29 a \\
(0.04)\end{array}$ & $\begin{array}{r}0.26 a \\
(0.04)\end{array}$ & $\begin{array}{c}0.23 \\
(0.03)\end{array}$ & $\begin{array}{c}0.26 a \\
(0.04)\end{array}$ & $\begin{array}{c}0.19 \\
(0.02)\end{array}$ & $\begin{array}{c}0.19 \\
(0.02)\end{array}$ & $\begin{array}{c}0.13 \\
(0.03)\end{array}$ & $\begin{array}{c}0.10 \\
(0.02)\end{array}$ & $\begin{array}{c}0.20 \\
(0.03)\end{array}$ & $\begin{array}{c}0.26 \\
(0.02)\end{array}$ & $\begin{array}{c}0.31 a \\
(0.02)\end{array}$ & $\begin{array}{r}0.30 \mathrm{a} \\
(0.02)\end{array}$ \\
\hline Drought & $\begin{array}{c}0.19 b \\
(0.02)\end{array}$ & $\begin{array}{c}0.18 b \\
(0.02)\end{array}$ & $\begin{array}{c}0.17 \\
(0.02)\end{array}$ & $\begin{array}{c}0.18 b \\
(0.02)\end{array}$ & $\begin{array}{c}0.16 \\
(0.01)\end{array}$ & $\begin{array}{c}0.18 \\
(0.01)\end{array}$ & $\begin{array}{c}0.13 \\
(0.01)\end{array}$ & $\begin{array}{c}0.09 \\
(0.02)\end{array}$ & $\begin{array}{c}0.20 \\
(0.01)\end{array}$ & $\begin{array}{c}0.23 \\
(0.02)\end{array}$ & $\begin{array}{c}0.20 \mathrm{~b} \\
(0.03)\end{array}$ & $\begin{array}{c}0.21 b \\
(0.03)\end{array}$ \\
\hline Warming & $\begin{array}{l}0.26 \mathrm{ab} \\
(0.04)\end{array}$ & $\begin{array}{l}0.22 \mathrm{ab} \\
(0.05)\end{array}$ & $\begin{array}{c}0.19 \\
(0.04)\end{array}$ & $\begin{array}{l}0.22 \mathrm{ab} \\
(0.05)\end{array}$ & $\begin{array}{c}0.17 \\
(0.03)\end{array}$ & $\begin{array}{c}0.17 \\
(0.01)\end{array}$ & $\begin{array}{c}0.11 \\
(0.01)\end{array}$ & $\begin{array}{c}0.11 \\
(0.02)\end{array}$ & $\begin{array}{c}0.20 \\
(0.02)\end{array}$ & $\begin{array}{c}0.26 \\
(0.03)\end{array}$ & $\begin{array}{c}0.29 \mathrm{a} \\
(0.03)\end{array}$ & $\begin{array}{c}0.29 \mathrm{a} \\
(0.03)\end{array}$ \\
\hline \multicolumn{13}{|l|}{2001} \\
\hline Control & $\begin{array}{c}0.33 a \\
(0.06)\end{array}$ & $\begin{array}{c}0.35 \\
(0.06)\end{array}$ & & $\begin{array}{c}0.21 \\
(0.03)\end{array}$ & $\begin{array}{c}0.21 a \\
(0.03)\end{array}$ & $\begin{array}{c}0.12 \\
(0.02)\end{array}$ & $\begin{array}{c}0.19 a \\
(0.04)\end{array}$ & $\begin{array}{l}0.10 \mathrm{ab} \\
(0.01)\end{array}$ & $\begin{array}{c}0.13 \\
(0.01)\end{array}$ & $\begin{array}{c}0.22 a \\
(0.01)\end{array}$ & $\begin{array}{r}0.26 a \\
(0.02)\end{array}$ & $\begin{array}{c}0.28 \\
(0.02)\end{array}$ \\
\hline Drought & $\begin{array}{c}0.23 b \\
(0.04)\end{array}$ & $\begin{array}{c}0.30 \\
(0.03)\end{array}$ & & $\begin{array}{c}0.17 \\
(0.01)\end{array}$ & $\begin{array}{c}0.15 b \\
(0.01)\end{array}$ & $\begin{array}{c}0.10 \\
(0.001)\end{array}$ & $\begin{array}{c}0.11 b \\
(0.01)\end{array}$ & $\begin{array}{c}0.09 a \\
(0.01)\end{array}$ & $\begin{array}{c}0.13 \\
(0.01)\end{array}$ & $\begin{array}{c}0.17 b \\
(0.02)\end{array}$ & $\begin{array}{c}0.21 b \\
(0.01)\end{array}$ & $\begin{array}{c}0.23 \\
(0.03)\end{array}$ \\
\hline Warming & $\begin{array}{l}0.32 \mathrm{ab} \\
(0.03)\end{array}$ & $\begin{array}{c}0.32 \\
(0.07)\end{array}$ & & $\begin{array}{c}0.20 \\
(0.02)\end{array}$ & $\begin{array}{l}0.19 \mathrm{ab} \\
(0.03)\end{array}$ & $\begin{array}{c}0.12 \\
(0.02)\end{array}$ & $\begin{array}{c}0.19 \mathrm{a} \\
(0.03)\end{array}$ & $\begin{array}{c}0.11 \mathrm{~b} \\
(0.004)\end{array}$ & $\begin{array}{c}0.13 \\
(0.01)\end{array}$ & $\begin{array}{c}0.21 \mathrm{a} \\
(0.02)\end{array}$ & $\begin{array}{c}0.26 a \\
(0.02)\end{array}$ & $\begin{array}{c}0.29 \\
(0.03)\end{array}$ \\
\hline \multicolumn{13}{|l|}{2002} \\
\hline Control & $\begin{array}{c}0.27 \\
(0.04)\end{array}$ & $\begin{array}{c}0.25 \\
(0.03)\end{array}$ & $\begin{array}{c}0.30 \\
(0.03)\end{array}$ & $\begin{array}{c}0.27 a \\
(0.02)\end{array}$ & $\begin{array}{c}0.26 a \\
(0.03)\end{array}$ & $\begin{array}{l}\text { 0.18ab } \\
(0.02)\end{array}$ & & & & & & \\
\hline Drought & $\begin{array}{c}0.26 \\
(0.03)\end{array}$ & $\begin{array}{c}0.23 \\
(0.02)\end{array}$ & $\begin{array}{c}0.29 \\
(0.02)\end{array}$ & $\begin{array}{c}0.24 b \\
(0.01)\end{array}$ & $\begin{array}{c}0.20 b \\
(0.02)\end{array}$ & $\begin{array}{c}0.14 a \\
(0.01)\end{array}$ & & & & & & \\
\hline Warming & $\begin{array}{c}0.29 \\
(0.03)\end{array}$ & $\begin{array}{c}0.24 \\
(0.02)\end{array}$ & $\begin{array}{c}0.30 \\
(0.03)\end{array}$ & $\begin{array}{c}0.28 \mathrm{a} \\
(0.01)\end{array}$ & $\begin{array}{c}0.27 a \\
(0.03)\end{array}$ & $\begin{array}{c}0.20 \mathrm{~b} \\
(0.02)\end{array}$ & & & & & & \\
\hline
\end{tabular}

The soil moisture was measured in three TDR probes installed in each plot. Different letters indicate significant differences between treatments (one-way ANOVA and post hoc Fisher's PLSD test). The months in which differences between drought treatment and control appeared are highlighted in bold characters.

Table 2 Effect of warming and drought treatments on air ( $20 \mathrm{~cm}$ above soil surface) and soil (10 cm below soil surface) temperature

\begin{tabular}{llllr}
\hline & \multicolumn{2}{l}{ Warming } & & \multicolumn{2}{l}{ Drought } \\
\cline { 2 - 3 } Hour & Soil & Air & Soil & Air \\
\hline 00:30-04:00 & $1.00(0.60)$ & $0.91(0.53)$ & $0.18(0.42)$ & $0.04(0.19)$ \\
04:30-08:00 & $1.18(0.65)$ & $1.12(0.65)$ & $0.18(0.40)$ & $0.19(0.25)$ \\
08:30-12:00 & $1.15(0.64)$ & $0.92(0.98)$ & $0.13(0.39)$ & $0.14(0.54)$ \\
12:30-16:00 & $0.72(0.72)$ & $0.21(1.17)$ & $0.04(0.49)$ & $0.15(0.77)$ \\
16:30-20:00 & $0.25(0.70)$ & $0.19(0.49)$ & $0.27(0.51)$ & $-0.15(0.44)$ \\
20:30-24:00 & $0.66(0.63)$ & $0.87(0.49)$ & $0.24(0.46)$ & $-0.21)$ \\
\hline
\end{tabular}

Values are the annual mean differences (SD in brackets) between warming and control plots, calculated from data collected daily from May 2000 to April 2001. In all cases (except for the effect of drought on air temperature from 20.30 to 24.00 hours), these values were significantly higher than zero (one sample $t$-test, $P<0.001, n=365$ days).

remained throughout most of the day, producing a significant increase in temperature both at soil level and in the layer of air close to the ground (Table 2), where an effect of climate warming on seedlings is to be expected. Smaller increases in temperature were also observed in drought treatments (Table 2).

The number of species with seedlings less than 1-year old present at the end of the emerging season was 
Table 3 Mean number of seedlings $\left(\mathrm{m}^{-2}\right)$ emerged in June 1999, June 2000, June 2001 and June 2002 in the different treatments

\begin{tabular}{|c|c|c|c|c|c|c|c|c|c|c|c|c|}
\hline \multirow[b]{2}{*}{ Species } & \multicolumn{3}{|l|}{1999} & \multicolumn{3}{|l|}{2000} & \multicolumn{3}{|l|}{2001} & \multicolumn{3}{|l|}{2002} \\
\hline & Con & War & Dro & Con & War & Dro & Con & War & Dro & Con & War & Dro \\
\hline Globularia alypum & 147.9 & 114.6 & 83.3 & 44.8 & 22.9 & 8.3 & 60.4 & 50.0 & 14.6 & 50.0 & 28.1 & 13.5 \\
\hline Erica multiflora & 5.2 & 6.3 & 2.1 & 11.5 & 11.5 & 0 & 151.0 & 114.6 & 5.2 & 46.9 & 118.8 & 10.4 \\
\hline Dorycnium pentaphyllum & 42.7 & 41.7 & 28.1 & 18.8 & 6.3 & 3.1 & 4.2 & 2.1 & 1.0 & 46.9 & 42.7 & 35.4 \\
\hline Fumana thymifolia & 67.7 & 32.3 & 22.9 & 21.9 & 11.5 & 5.2 & 36.5 & 11.5 & 11.5 & 14.6 & 12.5 & 14.6 \\
\hline Fumana ericoides & 22.9 & 16.7 & 36.5 & 14.6 & 9.4 & 12.5 & 28.1 & 16.7 & 14.6 & 17.7 & 17.7 & 16.7 \\
\hline Helianthemum syriacum & 71.9 & 10.4 & 7.3 & 24.0 & 6.3 & 0 & 11.5 & 24.0 & 6.3 & 8.3 & 21.9 & 2.1 \\
\hline Coris monspeliensis & 20.8 & 66.7 & 0 & 21.9 & 42.7 & 0 & 2.1 & 8.3 & 0 & 2.1 & 9.4 & 0 \\
\hline Polygala rupestris & 6.3 & 5.2 & 1.0 & 28.1 & 2.1 & 3.1 & 32.3 & 8.3 & 5.2 & 16.7 & 18.8 & 14.6 \\
\hline Argyrolobium zanonii & 8.3 & 5.2 & 7.3 & 0 & 5.2 & 1.0 & 3.1 & 1.0 & 2.1 & 2.1 & 1.0 & 3.1 \\
\hline Teucrium chamaedrys & 0 & 0 & 6.3 & 9.4 & 0 & 0 & 3.1 & 0 & 1.0 & 4.2 & 0 & 2.1 \\
\hline Ononis minutissima & 0 & 0 & 4.2 & 2.1 & 1.0 & 0 & 6.3 & 1.0 & 2.1 & 2.1 & 3.1 & 1.0 \\
\hline Rosmarinus officinalis & 2.1 & 0 & 0 & 1.0 & 0 & 0 & 10.4 & 0 & 0 & 0 & 0 & 0 \\
\hline Ulex parviflorus & 1.0 & 1.0 & 0 & 1.0 & 0 & 0 & 3.1 & 0 & 3.1 & 1.0 & 0 & 3.1 \\
\hline Coronilla minima & 2.1 & 0 & 1.0 & 0 & 0 & 0 & 0 & 0 & 0 & 0 & 0 & 0 \\
\hline Helichrysum stoechas & 0 & 0 & 0 & 0 & 1.0 & 0 & 0 & 2.1 & 0 & 0 & 0 & 0 \\
\hline Pistacia lentiscus & 0 & 0 & 0 & 0 & 0 & 0 & 1.0 & 0 & 1.0 & 0 & 1.0 & 0 \\
\hline Dorycnium hirsutum & 0 & 0 & 0 & 2.1 & 0 & 0 & 0 & 0 & 0 & 0 & 0 & 0 \\
\hline Thymus vulgaris & 1.0 & 0 & 0 & 0 & 0 & 0 & 0 & 0 & 0 & 1.0 & 0 & 0 \\
\hline Bupleurum fruticescens & 0 & 0 & 0 & 1.0 & 0 & 0 & 0 & 0 & 0 & 0 & 0 & 0 \\
\hline
\end{tabular}

Con: control; War: warming; Dro: drought.

significantly lower in the drought treatment (mean number of species in the eight quadrats per stand: 6.11, SD: 2.09) (repeated measures ANOVA, $F_{1,12}=17.88$, $P=0.013$ ) and in the warming treatment (mean: 7.78, SD: 1.72) (repeated measures ANOVA, $F_{1,12}=9.60$, $P=0.036$ ) than in the control stands (mean: 9.44, SD: 1.33) (Fig. 2a). The number of seedlings was also significantly lower in the drought treatment (mean number of seedlings in the eight quadrats per stand: 38.67, SD: 29.00) than in the control stands (mean: 87.56, SD: 46.36) (repeated measures ANOVA, $F_{1,12}=64.17$, $P=0.001$ ), but this was not the case in the warming treatment (mean: 77.89, SD: 50.68) (repeated measures ANOVA, $F_{1,12}=0.38, P=0.571$ ) (Fig. $2 b$ ).

Interyear variability was significant in species richness (number of species in the eight quadrats per stand, year 1999, mean: 7.89, SD: 1.45; year 2000, mean: 6.67, SD: 2.55; year 2001, mean: 6.44, SD: 2.24; year 2002, mean: 8.78, SD: 2.05) (repeated measures ANOVA, $F_{3,18}=4.24, P=0.020$ ), and in the number of emerging seedlings (number of seedlings in the eight quadrats per stand, year 1999 mean: 101.33, SD: 40.38; year 2000, mean: 38.11, SD: 28.24; year 2001, mean: 71.00, SD: 62.16; year 2002, mean: 64.67, SD: 48.71) (repeated measures ANOVA, $F_{3,18}=4.45, P=0.016$ ). No significant effect of treatments on the number of species was observed in those years $(1999,2002)$ with a low reduction of soil humidity due to drought and warming treatment (Fig. 2a) (spring 1999 and autumn 2001 to spring 2002; Table 1).

Survival analysis indicates that seedlings that emerged in 1999 under warming conditions were more likely to die over the course of the following 3 years than seedlings grown in control stands (survival analysis, Mantel-Cox test, $\left.\chi^{2}=5.91, P=0.015\right)$, but this effect is only due to high mortality during the first summer after establishment (Fig. 3a). There were no significant differences in the survival patterns between the drought and control stands (survival analysis, Mantel-Cox test, $\chi^{2}=1.23, P=0.268$ ). Survival analysis of the 2000 cohort over the course of the following 2 years did not show any significant differences between control and warming (survival analysis, MantelCox test, $\chi^{2}=0.53, P=0.466$ ) or drought treatments (survival analysis, Mantel-Cox test, $\chi^{2}=2.44, P=0.188$ ) (Fig. 3b).

As a result of the combined effect of the treatments on germination and seedling survival, in June 2002 the total number of established seedlings, which had emerged during the whole experimental period (excluding those that had just emerged in 2002) was significantly lower in the drought stands (mean number of seedlings in the eight quadrats per stand: 23.67, SD: 13.50) than in the control stands (mean: 65,00, SD: 13.75) (one-way ANOVA, $F_{1,4}=13.80, P=0.021$ ), but no significant differences were found between the warming 


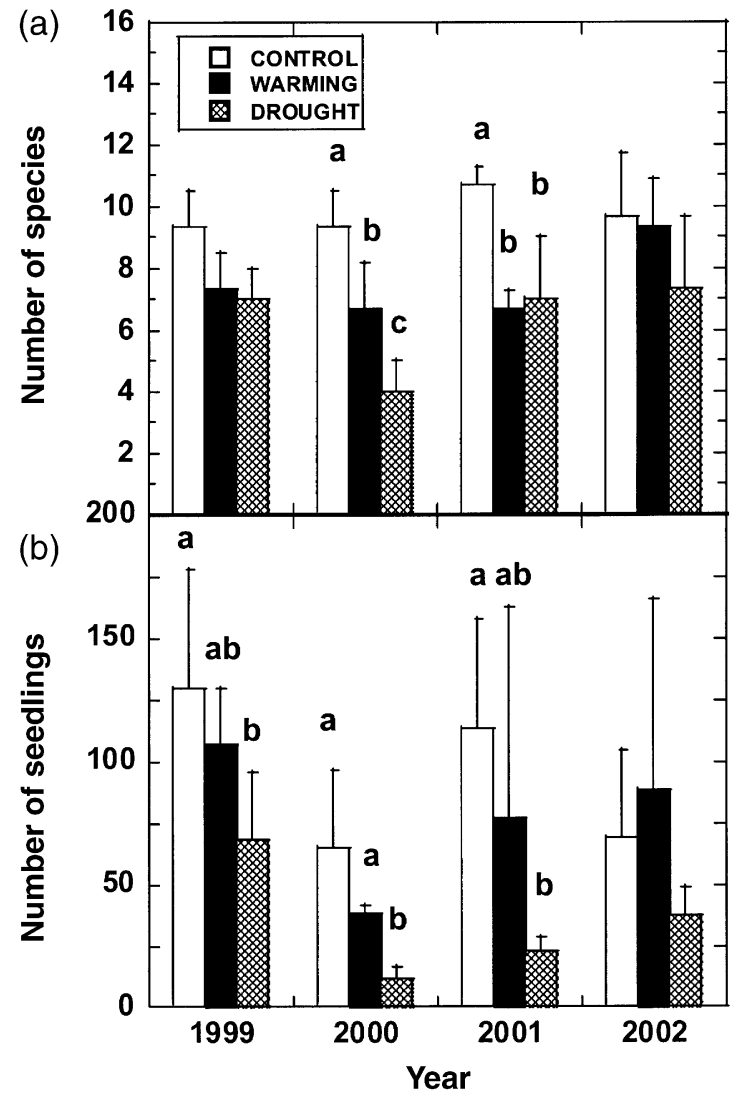

Fig. 2 Seedling recruitment in drought, warming and control plots. Species richness (a) and number of seedlings (b) less than 1-year old which were present at the end of the respective 1999, 2000, 2001 and 2001 emerging seasons (June). The values are the average of three stands per treatment. We pooled the results of eight $400 \mathrm{~cm}^{2}\left(20 \times 20 \mathrm{~cm}^{2}\right)$ quadrats in each stand. Bars are standard error $(n=3)$. Significance between treatments is indicated by different letters (Fisher's PLSD test, $P<0.05$ ).

(mean: 37.67, SD: 19.22) and control stands (post hoc Fisher's PLSD test, $P=0.0777$ ).

There was no difference in species evenness, estimated from the $H^{\prime}$ Shannon index, with respect to the treatment stands (drought, mean $H^{\prime}$ in the eight quadrats per stand: 0.82 , SD: 0.79; warming, mean: 0.75 , SD: 0.16) and control stands (mean: 0.79, SD: 0.80) (repeated measures ANOVA, drought vs. control: $F_{1,12}=2.49, \quad P=0.190 ;$ and warming vs. control: $F_{1,12}=0.11, P=0.752$ ).

There was a significant, positive linear correlation between the relative abundance of species in the warming and control stands (Fig. 4). In the drought treatments, the relationship of the relative abundance of species between treatment and control is not so constant over the years. We found both positive (1999 and 2002 cohorts) and nonsignificant correlations (2000 and 2001 cohorts). The species-rank abundance in the

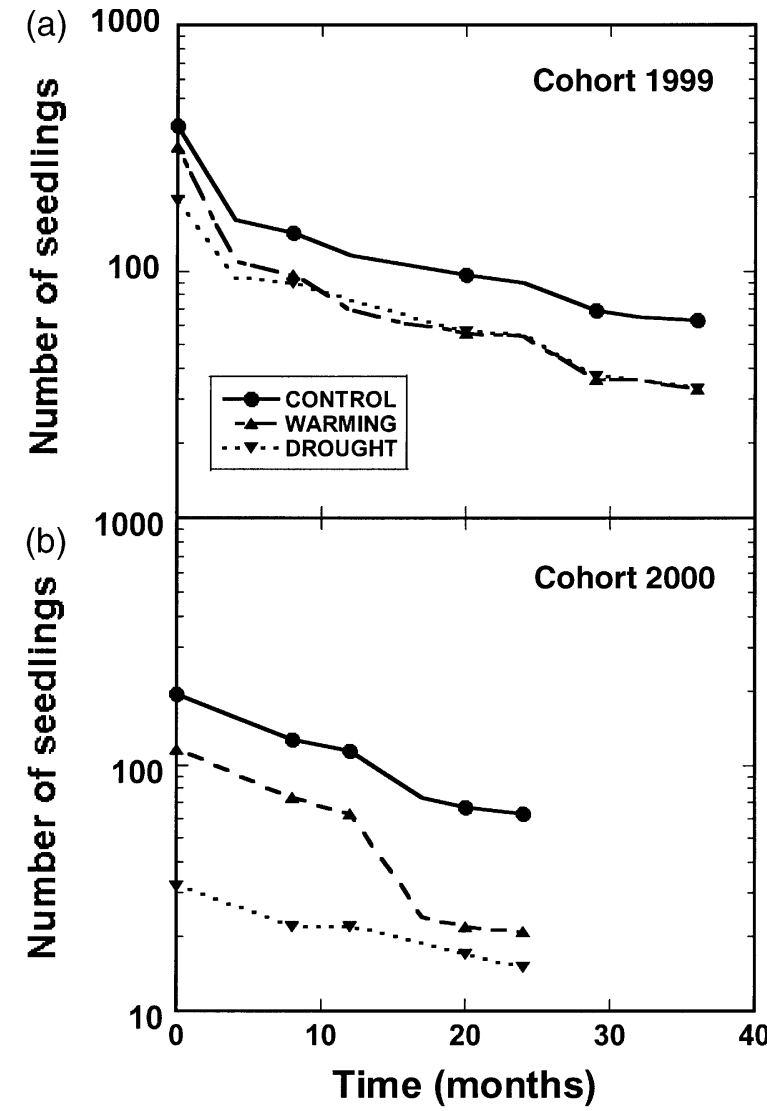

Fig. 3 Seedling survival (logarithmic scale) of the 1999 (a) and 2000 (b) cohorts in drought, warming and control plots. Survival of each individual seedling was tracked from the end of the respective growing season (June) to June 2002. Data of the three stands per treatment have been pooled. Significant differences $(P<0.05)$ were only found between warming treatment and control in the 1999 cohort (Mantel-Cox test.).

control plots did not exert any significant effect on the likelihood of increase or decrease in rank in the drought stands (logistic regression, 1999: Wald $\chi^{2}=1.29$, $P=0.526$; 2000: Wald $\chi^{2}=2.95, P=0.086$; 2001: Wald $\chi^{2}=1.42, P=0.491 ; 2002$ : Wald $\left.\chi^{2}=0.77, P=0.379\right)$ or the warming stands (logistic regression, 1999: Wald $\chi^{2}=3.06, P=0.216 ;$ 2000: Wald $\chi^{2}=0.49, \quad P=0.782$; 2001: Wald $\chi^{2}=2.08, P=0.354 ;$ 2002: Wald $\chi^{2}=2.48$, $P=0.291$ ). There were no significant effects of the year on the differences in species-rank abundance between the control and drought (repeated measures ANOVA, $\left.F_{3,27}=0.04, P=0.989\right)$ and the control and warming $\left(F_{3,33}=0.11, P=0.956\right)$ treatments.

\section{Discussion}

The treatments significantly modified climatic conditions at stand level. However, they did not induce any 


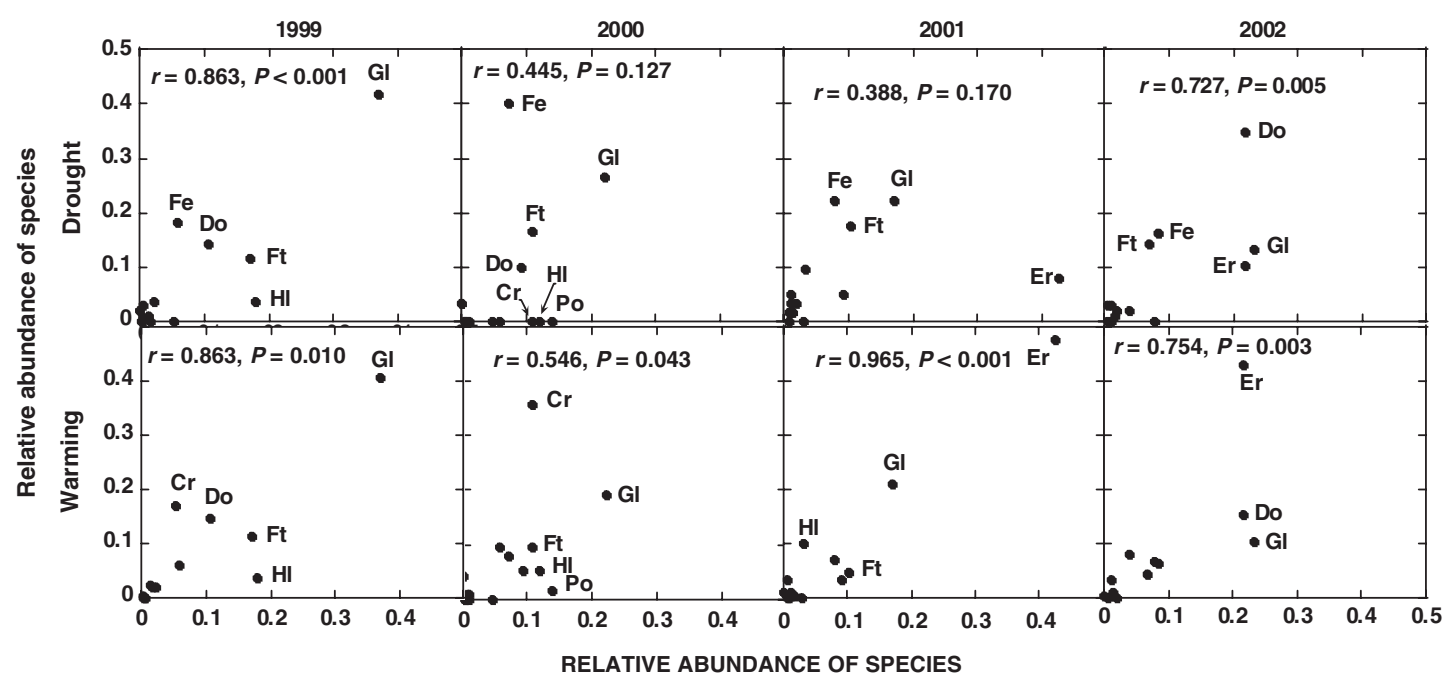

Fig. 4 Relationships between the relative abundance of species in treatment (warming and drought) and control stands for seedlings less than 1-year old present at the end of the respective 1999, 2000, 2001 and 2002 emerging seasons. Significance and $r$-values correspond to linear correlation. Name of the species with relative abundances higher than 0.1 in any of the control or treatments are indicated: Cr: Coris monspeliensis; Do: Dorycnium pentaphyllum; Er: Erica multiflora; Fe: Fumana ericoides; Ft: Fumana thymifolia; Gl: Globularia alypum; Hl: Helianthemum syriacum; Po: Polygala rupestris.

constant rates of change in temperature or water availability, as they followed the climatic variability, both within and between the different years. The drought treatment was thus more effective in those seasons in which water exclusion was concurrent with more rainfall events, as in the fall 1999-spring 2000 and fall 2000-spring 2001 periods. This variability in the climatic conditions can also be expected to determine the interyear variability in seedling establishment. Reduced moisture input in water exclusion stands also induces some slight warming, although this effect is mostly limited to the rain periods, when the treatment was active. The warming roofs may also intercept rain, thereby reducing soil moisture. However, the warming roofs may create the opposite effect on soil moisture by decreasing evaporation. Overall, we did not find any significant reduction in soil moisture in the warming plots, although the values were often lower. However, the collateral effects of the warming treatment on soil moisture, and of the drought treatment on temperature, are minor in comparison to the main effects of the drought and warming treatments on soil moisture and temperature, respectively. We will focus our discussion on these main effects, as they are difficult to distinguish.

Our results indicate that the number of emerging seedlings and their associated species richness diminished as a consequence of decreased availability of water, a limited resource in Mediterranean ecosystems that is closely linked to climate conditions (Piñol et al., 1995). Our experiment excluded rainfall in autumn and spring-early summer, the seasons when most seedling emergence occurs. Decreasing the water from rainfall thus had a significant effect on seed germination, as has also been reported for some Mediterranean trees after recording recruitment over successive years (Borchert $e t$ al., 1989; Herrera et al., 1994). These results are particularly important for forecasting future changes within the community, because most of these species depends on seedling recruitment to maintain their populations. Asexual recruitment is not common in these species, except after wildfires (Lloret, 1998). Although fire regime is an important driving force for vegetation changes in these types of communities, the long-term dynamics of Mediterranean shrublands are largely determined by the plant establishment that occurs in periods without fire (Keeley, 1992; Lloret et al., 2003).

Our results suggest that plant recruitment in this Mediterranean-type community may decrease in new climate scenarios of increasing drought (Rambal \& Debussche, 1995; IPCC, 2001). It should be noted, however, that our results were obtained from induced drought in the seasons that are most critical for seedling establishment. Although we cannot exactly predict the future composition of the community from changes in seedling dynamics (mortality of established adults, gap opening, species interactions and growth rates are also involved in the process of obtaining dominance), in so far as the plant community renewal depends on the former seedling stage, we can at least state that a decrease in the number of species at this stage will 
impair the community's long-term ability to withstand more stressful climatic conditions.

Induced climate-change experiments in mountain areas have shown that warming may enhance the number of recruiting seedlings, but they have not considered the consequences on species diversity (Harte \& Shaw, 1995). In our study, warming treatment produced an intermediate decrease in seedling species recruitment, with respect to the values observed for the control and drought treatments, but no significant differences were observed between the number of emerging seedlings in the warming and control treatments. This warming effect seems to be more closely linked to water availability than to warming itself, since temperature is not expected to be a limiting factor for germination in Mediterranean-type ecosystems.

The drought treatment has a contrasting effect on the two development stages considered in the study: seedling establishment and the survival of established seedlings. Drought decreased the number of seedlings that emerged, but the treatment did not increase mortality once they had been established. Noncoupled success in different stages of the life cycle in the face of specific environmental constraints has been documented in relation to the establishment process in other studies (Schupp, 1995; Houle, 1998; Vilà \& Lloret, 2000), and Weltzin \& McPherson (2000) obtained a similar pattern in the woodland/semi-arid grassland ecotones in southwestern North America. The seedling root systems of most species rapidly achieve more than $10 \mathrm{~cm}$ of depth in the soil, increasing their ability to take up water under drier conditions. However, seed germination is highly dependent on water content in soil layers closer to the surface. Nevertheless, further studies need to be undertaken to ascertain whether plants that have emerged under drought conditions are better able to survive in comparison to plants from seeds germinating in standard conditions, when both kinds of plants are growing with a limited water supply; i.e., if drought can select at the germination stage for plants able to survive further drought conditions.

There was a significant, positive linear correlation in our study between the relative abundance of species in the warming and in control stands. These results indicate that species which become less abundant in warming treatments are also the least abundant in control stands, suggesting that species currently producing fewer recruits are more likely to disappear from the community in new, warmer climatic scenarios. This positive correlation supports the sampling hypothesis (species losses are proportional to species abundance) as opposed to the idiosyncratic hypothesis (no relationship between species losses and species abundance).
Furthermore, species do not change from year to year in terms of their rank abundance, as would be expected if species fluctuated widely in accordance with the idiosyncratic hypothesis. The selection hypothesis (the less abundant species are more likely to disappear) was not supported by the patterns of species evenness, as calculated from the $H^{\prime}$ Shannon index, as this did not present any differences between the treatments and the control stands. Moreover, species-rank abundance was not found to be a good predictor of seedling decline and, therefore, failed to support the selection hypothesis. Although this selection hypothesis might be sustained when adult populations are considered, seedling production is not only triggered by climatic conditions, it may be also largely dependent on species life history. The shift hypothesis (more abundant species are more likely to disappear) is refuted by both this relationship between the relative abundance of species in the treatment and control stands and by the rank abundance analysis.

In the drought treatments, the relationship between the relative abundance of species in treatment and control shows different interyear patterns, ranging from a positive to a nonsignificant correlation, although no significant interyear differences in rank-abundance patterns were observed. Therefore, both the sampling and the idiosyncratic hypotheses may explain the species-abundance decrease as a consequence of drought treatments. The interyear climatic variability may determine the relative importance of the sampling or idiosyncratic effects, as observed in 2000 and 2001, when the effect of the drought treatments on soil humidity was greater.

Although our data are not completely conclusive, they suggest that when there is a dramatic loss of individual plants, as in the drought treatment in 2000 and 2001, the species-specific responses to drought may determine the pattern of species relative abundance in the community. In other words, our ability to predict which species will be more abundant from previous abundance patterns is substantially reduced. In our case, the relative abundance of $F$. ericoides seedlings increased in drought stands, regardless of their abundance in the control stands. The opposite trend (decrease in drought treatment) was observed in $E$. multiflora. However, the behaviour of different species was not the same in the drought and warming treatments. In addition to F. ericoides, two other species (A. zanonii and D. pentaphyllum) increased under drought treatment, while $C$. monspeliensis and E. multiflora increased under warming treatment. The species decreasing under drought were C. monspeliensis, $P$. rupestris and E. multiflora, while those decreasing under warming were $A$. zanonii and F. thymifolia. In addition to 
species-abundance patterns, the biological attributes of plants can reflect ecological constraints at the community level, and plant functional traits may be used to predict community response to climate change (Lavorel et al., 1997; Díaz \& Cabido, 1997). Functional attributes in the early stages of establishment have still received little attention, even though they may be quite different from the patterns displayed by adults. Further exploration of the effects of climate manipulation on the spectrum of seedlings' functional traits would reveal valuable information for predicting future changes in the community.

Our work shows that species diversity in the stages of recruitment into the community decreased when conditions that are drier than the present ones remained operative for several years. Warming also diminished the species diversity of recruiters, even though the temperature rise was moderate. However, the relationship between the species abundance (or rarity) of seedlings and their respective likelihood of disappearing under new climatic conditions warrants further exploration. In the absence of data on the effect of changing climatic conditions on new species' rates of migration into the community, our results suggest that new dominance patterns may appear at the recruitment stage when a threshold of drier conditions allows the more tolerant species in the existing community to achieve dominance.

\section{Acknowledgements}

We thank C. Beier, B. Emmett and A. Tietema for sharing information on the experimental setting; L. Llorens, P. Bruna and E. Romero for field assistance; Garraf Natural Park staff for permission to carry out the study and assistance in putting it into practice. We also thank two anonymous reviewers for their suggestions. This work was supported by EU grants (CLIMOOR ENV4-CT97-0694 and VULCAN EVK2-CT-2000-00094) and Spanish MCYT grants (REN2000-0278/CCI and REN2001-003/ GLO).

\section{References}

Alward RD, Detling JK, Milchunas DG (1999) Grassland vegetation changes and nocturnal global warming. Science, 283, 229-231.

Anon (1998) StatView 5.0.1. SAS Institute Inc., Cary, NC, USA.

Beier C, Gundersen P, Nielsen TR et al. (2004) Passive night time warming - a novel technique to study climate change effects on terrestrial ecosystems at field scale. Ecosystems (in press).

Borchert MI, Davis FW, Michaelsen J, Oyler LD (1989) Interactions of factors affecting seedling recruitment of blue oak (Quercus douglasii) in California. Ecology, 70, 389-404.

Buckland SM, Thompson K, Hodgson JG et al. (2001) Grassland invasions: effects of manipulations of climate and management. Journal of Applied Ecology, 38, 301-309.
Chapin III FS, Sala OE, Huber-Sannwald E (2001) Global Biodiversity in a Changing Environment. Springer, New York.

Chapin III FS, Shaver GR, Giblin AE et al. (1995) Response of arctic tundra to experimental and observed changes in climate. Ecology, 76, 694-711.

Díaz S, Cabido M (1997) Plant functional types and ecosystem function in relation to global change. Journal of Vegetation Science, 8, 463-474.

Easterling DE, Horton B, Jones PD et al. (1997) Maximum and minimum temperature trends for the Globe. Science, 277, 364367.

Fay PA, Carlisle JD, Knapp AK et al. (2000) Altering rainfall timing and quantity in a mesic grassland ecosystem: design and performance of rainfall manipulation shelters. Ecosystems, 3, 308-319.

Harte J, Shaw R (1995) Shifting dominance within a montane vegetation community: results of a climate-warming experiment. Science, 267, 876-880.

Henry GHR, Molau U (1997) Tundra plants and climate change: The International Tundra Experiment (ITEX). Global Change Biology, 3, 1-9.

Herrera CM, Jordano P, López-Soria L et al. (1994) Recruitment of a mast-fruiting, bird-dispersed tree: bridging frugivore activity and seedling establishment. Ecological Monographs, 64, 315-344.

Houle G (1998) Seed dispersal and seedling recruitment of Betula alleghaniensis: spatial inconsistency in time. Ecology, 79, 807-818.

IPCC (2001) Third Assessment Report of Working Group I. Climate Change 2001: The Scientific Basis. Cambridge University Press, Cambridge.

Iverson LR, Prasad AM (1998) Predicting abundance of 80 tree species following climate change in the Eastern United States. Ecological Monographs, 68, 465-485.

Karl TR, Jones PD, Knight RW et al. (1993) Assymetric trends of daily maximum and minimum temperature. Bulletin American Metereological Society, 74, 1007-1023.

Keeley JE (1992) Recruitment of seedlings and vegetative sprouts in unburned chaparral. Ecology, 73, 1194-1208.

Körner C (2000) Biosphere responses to $\mathrm{CO}_{2}$ enrichment. Ecological Applications, 10, 1590-1619.

Kullman L (2002) Rapid recent range-margin rise of tree and shrub species in the Swedish Scandes. Journal of Ecology, 90, 68-77.

Larcher W (2000) Temperature stress and survival ability of Mediterranean sclerophyllous plants. Plant Biosystems, 134, 279-295.

Lavorel S, McIntyre S, Landsberg J et al. (1997) Plant functional classifications: from general groups to specific groups based on response to disturbance. Trends Ecology and Evolution, 12, 474-478.

Lewis-Smith RI (1994) Vascular plants as bioindicators of regional warming in Antarctica. Oecologia, 99, 322-328.

Lloret F (1998) Fire, canopy cover and seedling dynamics in Mediterranean shrubland of northeastern Spain. Journal of Vegetation Science, 9, 417-430.

Lloret F, Pausas JG, Vilà M (2003) Responses of Mediterranean plant species to different fire frequencies in Garraf Natural Park (Catalonia, Spain): field observations and modeling predictions. Plant Ecology, 167, 223-235. 
Luekewille A, Wright RF (1997) Experimentally increased soil temperature causes release of nitrogen at a boreal forest catchment southern Norway. Global Change Biology, 3, 13-21.

Parmesan C, Ryrholm N, Stefanescu C et al. (1999) Poleward shifts in geographical ranges of butterfly species associated with regional warming. Nature, 399, 579-583.

Parsons AN, Press MC, Wookey PA et al. (1995) Growth responses of Calamagrostis lapponica to simulated environmental change in the sub-arctic. Oikos, 72, 61-66.

Peñuelas J, Boada M (2003) A global change-induced biome shift in the Montseny Mountains (NE Spain). Global Change Biology, 9, 131-140.

Peñuelas J, Gordon C, Llorens L et al. (2004) Non-intrusive field experiments show different plant responses to warming and drought among sites, seasons and species in a North-South Eurpean gradient. Ecosystems (in press).

Piñol J, Terradas J, Avila A, Rodà F (1995) Using catchments of contrasting hydrological conditions to explore climate effects on water and nutrient flows in Mediterranean forests. In: Global change and Mediterranean-Type Ecosystems (eds Moreno JM, Oechel WC), pp. 371-385. Springer-Verlag, New York.

Rambal S, Debussche G (1995) Water balance in mediterranean systems in a changing climate. In: Global Change and Mediterranean-Type Ecosystems (eds Moreno JM, Oechel WC), pp. 386-407. Springer-Verlag, New York.

Rasmussen L, Beier C, Bergstedt A (2002) Experimental manipulations of old pine forest ecosystem to predict the potential tree growth effects of increased $\mathrm{CO}_{2}$ and temperature in a future climate. Forest Ecology Management, 158, 179-188.

Robinson CH, Wookey PA, Lee JA et al. (1998) Plant community responses to simulated change at a high arctic polar semidesert. Ecology, 79, 856-866.

Schulze ED, Mooney HA, Sala OE et al. (1996) Rooting depth, water availability, and vegetation cover along an aridity gradient in Patagonia. Oecologia, 108, 503-511.

Schupp EW (1995) Deed-seeding conflicts, habitat choice, and patterns of plant recruitment. American Journal of Botany, 82, 399-409.

Shaver GR, Canadell J, Chapin III FS et al. (2000) Global warming and terrestrial ecosystems: a conceptual framework for analysis. BioScience, 50, 871-882.

Shaw MR, Harte J (2001) Control of litter decomposition in a subalpine meadow-sagebrush steppe ecotone under climate change. Ecological Applications, 11, 1206-1223.

Specht RL, Moll EJ, Pressinger F, Sommerville J (1983) Moisture regime and nutrient control of seasonal growth in Mediterra- nean ecosystems. In: Mediterranean-Type Ecosystems. The Role of Nutrients (eds Kruger FJ, Mitchell DT, Jarvis JUM), pp. 120132. Springer-Verlag, Berlin.

Sternberg M, Brown VK, Masters GJ et al. (1999) Plant community dynamics in a calcareous grassland under climate change manipulations. Plant Ecology, 143, 29-37.

Sykes MT, Prentice C, Cramer W (1996) A bioclimatic model for the potential distributions of north European species under present and future climates. Journal of Biogeography, 23, 203-233.

Taylor AH (1995) Forest expansion and climate change in the mountain hemlock (Tsuga martensiana) zone, Lassen Volcanic National Park, California, U.S.A. (1995). Arctic Alpine Research, 27, 207-216.

Tilman D (1998) Species composition, species diversity, and ecosystem processes: understanding the impacts of global change. In: Successes, Limitations, and Frontiers in Ecosystem Science (eds Pace ML, Groffman PM), pp. 452-472. Springer, New York.

Valpine P de, Harte J (2001) Plant responses to experimental warming in a montane meadow. Ecology, 82, 637-648.

Vilà M, Lloret F (2000) Seed dynamics of the mast seeding tussock grass Ampelodesmos mauritanica in Mediterranean shrublands. Journal of Ecology, 88, 479-491.

Walther GR, Burga CA, Edwards PJ), (eds.) (2001) 'Fingerprints' of Climate Change. Adapted Behaviour and Shifting Species Ranges. Kluwer, New York.

Warren MS, Hill JK, Thomas JA et al. (2001) Rapid response of British butterflies to opposing forces of climate and habitat change. Nature, 414, 65-68.

Watkinson AR (1997) Plant population dynamics. In: Plant Ecology, 2nd edn (ed Crawley MJ), pp. 359-400. Blackwell Science, Oxford.

Weltzin JF, McPherson GR (2000) Implications of precipitation redistribution for shifts in temperate savanna ecotones. Ecology, 81, 1902-1913.

Weltzin JF, Pastor J, Harth C et al. (2000) Response of bog and fen plant communities to warming and water-table manipulation. Ecology, 81, 3464-3478.

Wookey PA, Robinson CH, Parsons AN et al. (1995) Environmental constraints on the growth, photosynthesis and reproductive development of Dryas octopetala at a high Arctic polar semi-desert, Svalbard. Oecologia, 102, 478-489.

Wright RF (1998) Effect of increased carbon dioxide an temperature on runoff chemistry at a forested catchment in southern Norway (CLIMEX Project). Ecosystems, 1, 216-225. 